\title{
The Financial Impact of Risk Factors Affecting Project Cost Contingency: Evidential Reasoning Method
}

\author{
Joseph Ignatius Teye Buertey ${ }^{1}$, Emmanuel Abeere-Inga ${ }^{2}$, and Theophilus Adjei Kumi ${ }^{3}$ \\ ${ }^{1} \mathrm{PhD}$ Student, Open University of Malaysia and Lecturer, Pentecost University college, Ghana P. O. Box KN 1739, \\ Kaneshie, jbuert@yahoo.co.uk (Corresponding author) \\ ${ }^{2}$ Director of Programs, CaRoRa Consult, Box CT 2O41, Ghana and Lecturer Accra Institute of Technology, Accra, \\ abeereinga@hotmail.com
}

${ }^{3}$ Lecturer, Department of Building Technology, Kwame Nkrumah University of Science and Technology, U.P.O, Kumasi, Ghana, tadjeikumi@yahoo.com

Project Management

Received August 7, 2012; received revisions October 4, 2012; October 9, 2012; November 7, 2012; November 25, 2012; accepted

November 26, 2012

Available online January 13, 2013

\begin{abstract}
The process of cost modeling using risk analysis for construction projects is very crucial for the achievement of project success. The purpose of this paper is to present an analysis of the financial impact of risk factors affecting key construction work sections; using a systematic risk methodology based on empirical judgment. The failure mode effect analysis (FMEA) and the evidential reasoning methods are presented as qualitative and quantitative risk tools respectively. Data analysis from structured questionnaires revealed that four work sections are prone to high scope changes contemporaneous with seven risk factors. Contrary to the usual $10 \%$ contingency estimate allowed for construction projects in Ghana, an approximate overall physical contingency range of between $13.36 \%$ and $17.88 \%$ was determined using evidential reasoning methods. The likely impact of the integrated work sections and risk factors provide a clue to estimators on how to estimate and account for project cost contingency. The research concludes by recommending a framework for improving the estimation process of cost contingency through the integration of efficient risk management strategies, cost estimation and design management process.
\end{abstract}

Keywords: Work sections, epistemic uncertainty, project specific risk, systemic risk, cost risk, evidential reasoning methods and contingency.

\section{Introduction}

Risk and uncertainty are two misconstrued concepts but distinct in nature. Whereas risk is upheld as an uncertain discrete event which can be estimated using probabilistic analysis, uncertainty is associated with an uncommon state of nature characterized by the absence of any information related to a desired outcome. It is the gap between the information required to estimate an outcome and the information already posed by the decision maker.

Oyewobi et al. (2012) holds that risk is an inseparable part of construction projects. Wishnu and Pradodno (2011), hold that risk analysis is a process of either using qualitative or quantitative methods involving measurement of uncertainty and risk impact. Perminpova et al. (2008) postulate risk as an event that could have either a negative impact on the project outcomes, or opportunities that are beneficial to the project performance. Risk is inherent in nearly every decision one takes and it has the potential of impacting on the project. Thus risk management is a process which enables a risk - taker to pursue an informed approach to a risk situation, with a view of controlling risk or optimizing decision about risk. Thus risk can be observed to be made up of two events: the likelihood of something happening and the magnitude of the consequence if it did. Risk is dynamic because two elements of risk: probability and outcome are not necessarily fixed over time. Some probability associated with risk may increase or decrease with the passing of time, according to their impact. Oyewobi et al. (2012) affirms that the commencement of construction projects results in the emergence of certain inherent risk which Buertey et al. (2012a) calls systemic and project specific risk.

According to Tah and Carr (2000), the construction industry is often greatly plagued by risk. This risk if not dealt with adequately, usually results in poor project performance. Generally, every activity of the construction process is associated with risk. For example the phases of designing and execution are saddled with a certain degree of imprecision usually compounded by poor, incomplete and inconsistent communication of construction project risk. According to Nasirzadeh et al. (2008), construction 
projects involve a large number of risks which have an extensive complex structure arising from multiple interdependent components. The characteristics of these have an impact on the overall likelihood of occurrence through a cause and effect feedback loop. The above may further be escalated by the overall effect of indirect and secondary risk as offspring from other risk. Since risk is a major factor to be considered during the management of every project, risk management is expectant integral aspect of project management which requires further research. Studies by Ogunsanmi et al. (2011) revealed 37 risk factors that affect the design and project concluding that designers and contractors should watch out for cost overruns and poor quality as major risk categories

Though every phase of the construction process requires risk application, the estimation process of construction cost contingency most often lack a scientific basis. Keith (2011) revealed that there is no evidence of formal standardized models or prescriptive contingency management method, or advanced objective analysis tools directed at the contingency management. To determine a realistic contingency margin, Ali (2005) holds that this must be estimated using the estimating or risk management process, which he recommended for further research.

\subsection{Theoretical Framework}

Over the years, various risk models have been developed including the probability theory, fuzzy logic theory, analytical hierarchical process, decision theory, sensitivity analysis, additive models, system dynamics, expected monetary values (EMV), multivariate statistical models, simulation, artificial Neural Networks (ANNs), theory of constraints amongst others. The theoretical basis for this research is the theory of evidence variously called the Dempster Shaffer theory (DST). Rakowsky (2007) underscored that DST is a mathematical theory of evidence concept that is built around degrees of belief rather than probabilities. It is based on scenarios that contain the system of hypotheses, pieces of evidence and data sources. The hypotheses are possible states of elements (singleton) of the frame of discernment, which is given by the finite universal set $\Omega$. The set of all subset of $\Omega$ is its power set $2 \Omega$. DST assumes qualitative relationship between a piece of evidence and hypotheses corresponds to a cause consequence chain. Rakowsky (2007) postulates that for the DST, data sources are people or organizations or any other entity that provides information for a scenario. Since the DST calculus describes the subjective viewpoint for an objective fact, data sources must be representative and free of bias.

According to Rakowsky (2007) based on data sources which is representative and free from bias, DST calculus is estimated by means of mapping:

$m: 2^{\Omega} \rightarrow[0,1]$

With $m(\mathrm{~A})>0$ called the focal element.

The function $m$ is called the basic assignment and fulfils:

$\sum_{\mathrm{AC \Omega} \Omega} m(\mathrm{~A})=1$

By creating the basic assignment function, several evidential functions can be created. A belief measure is given by the function bel: $m: 2^{\Omega} \rightarrow[0,1]$. There is

$\operatorname{Bel}(\mathrm{A})=\sum_{\mathrm{ACA} ; \mathrm{B} \neq \varnothing \Omega} m(\mathrm{~B})$
$\operatorname{Bel}(\neg \mathrm{A})=1-P l(A), P l(A)=1-b e l(\neg \mathrm{A})$

With bel $(\neg \mathrm{A}) \leq p l(\neg \mathrm{A})$

Uncertainty is construed as the difference between $p l$ $(\neg \mathrm{A})$ and bel $(\neg \mathrm{A})$

The counterpart of belief is plausibility measure

pl: $2^{\Omega} \rightarrow[0,1]$, with

$P l(\mathrm{~A})=\sum_{\mathrm{A} \cap \mathrm{B} \neq \emptyset \mathrm{m}(\mathrm{B})=1}$

The measure of $\mathrm{pl}(\mathrm{A})$ is not understood as the complement of bel (A). Only

$\{\mathrm{A} C \Omega \mid \mathrm{m}(\mathrm{A})>0\} \neq \emptyset \rightarrow \operatorname{bel}(\mathrm{A}) \leq \mathrm{pl}(\mathrm{A})$

Thus the difference between $P(A)$-bel (A) describes the evidential interval range which represents the uncertainty concerning the set A.

\subsection{Conceptual Framework}

Construction projects are becoming increasingly complex and dynamic in nature. With the introduction of emerging procurement methods contractors may have to rethink their approach to the risk treatment within their project and organization (Tar and Car, 2000). Aven, (2008) hold the view that there is lack of knowledge of what analysts express and what the meaning of uncertainty is, even among experienced practitioners. The above is claimed to have serious implications for decision making possibly affecting the choice of the option to mitigate the risk.

Thus the challenge of adequately managing cost and risk of infrastructural projects have impact on its success otherwise. Buertey et al. (2012b) holds that since in the construction industry, scope definition is hardly $100 \%$ complete at the project take-off, the allocation of cost contingency for projects is inevitable. Buertey et al. (2002b) further postulated that out of the four types of construction cost contingencies, design contingencies are used to minimise the error due to estimations and design arising from insufficiencies in scope, lack of design completeness, and uncertainties in construction technology, design changes and growth result from uncertain conditions. Construction process contingency on the other hand estimates the risk associated with the uncertainties in the process of construction (Buertey et al. 2002b). Keith (2011) confirmed Rifat (2005) assertion that the construction industry lacks standardized methods of estimating cost contingency making the estimation process deterministic. These authors held that though various models have been developed over the years, none of them seems to satisfy the built environment expressively.

Buertey et al. (2012c) revealed that a cursory verification of current practice with respect to project cost estimation and documentation in Ghana shows that about $90 \%$ of previous projects used $10 \%$ contingency allowance/ reserve, some $8 \%$ used $5 \%$ and the last $2 \%$ used margins greater than $15 \%$. Some $0.2 \%$ of project based their contingency figure independent of the contractor's estimate. The survey further revealed that consultants who compiled project documentation had no scientific basis for the figures used and emphasised that these judgments were based on experience and historical data. The above percentages are devoid of any risk assessment to mitigate any uncertainties. Ideally, contingency fund development is to be based on project 
risk parameters, the major cost elements, expert surveys, enterprise environmental factors, organizational process asset determined through qualitative and quantitative risk assessment (Rifat, 2005).

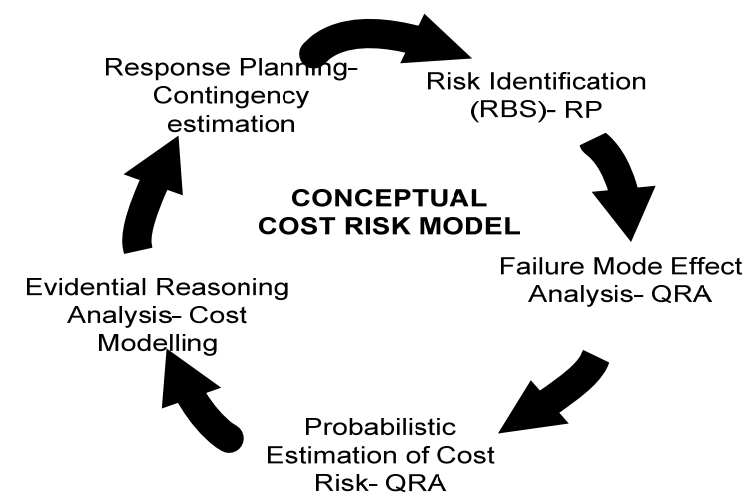

Fig. 1. Conceptual model

Source: Author's construct

The conceptual risk frame work in Fig. 1 below displays the graphical representation of the proposed risk management process. The conceptual model proposes that the estimating of cost contingency should go through a systematic evolving process of risk planning qualitative risk analysis, quantitative risk analysis, cost modeling, cognitive risk response planning and subsequent monitoring, control and provide feedback to fine tune the process. Risk management is thus recommended to run through the entire project trajectory in a cyclical and evolutionary trend.

In the light of the above, Keith (2005) proposed the estimation of contingency using a three tier risk analysis. The process for risk type 1 was explained as risk identification using contingency and percentage. Risk type II was explained as qualitative risk analysis to identify contingency items; whilst risk type III was identified as quantitative risk analysis and active contingency management. Keith (2011) further affirmed that uncertainty in cost growth decreases as one travels along the project trajectory with significant risk unveiling. The distinction between known-known (quantifiable cost), known-unknown (known but non- quantifiable cost) and unknown-unknown (unrealized uncertain cost) brings to fore the need for contingency and management allowance. The three tier risk management process forms the beginning of the conceptual framework in Fig. 1.

During project execution, a comprehensive contingency management strategy should be put in place which includes the management of secondary and residual risk. The project team should watch out for secondary and residual risk which has the potential of derailing project cost. These risks should be communicated to other team members immediately risk triggers are identified.

\section{Research Method}

\subsection{Research Aim and Population}

The aim of the above descriptive research is to determine using evidential methods, the financial impact of high priority risk and the impact of key work sections prone to high scope changes. Based on the above, an overall heuristic research was undertaken to determine the adequacy contingency margins charged in Ghana. The paper adopted quantitative methods with a survey questionnaire administered to stakeholders and professionals in the built environment in Ghana. The sample size for this work was determined using the statistical relation by Kumar (1999); Clarke and Cook (1998). In all, 204 questionnaires were distributed and $118(57.8 \%)$ were retrieved as depicted in Table 1.

Table 1. Questionnaire distribution by demography

\begin{tabular}{cccc}
\hline $\begin{array}{c}\text { Type of } \\
\text { Respondent }\end{array}$ & $\begin{array}{c}\text { Total } \\
\text { Out }\end{array}$ & $\begin{array}{c}\text { No. of } \\
\text { Responses }\end{array}$ & $\begin{array}{c}\text { Proportion of } \\
\text { total Sample } \\
\text { Size (\%) }\end{array}$ \\
\hline $\begin{array}{c}\text { Consultants } \\
\text { Client's }\end{array}$ & 115 & 58 & $50.43 \%$ \\
firms & 40 & 34 & $85.00 \%$ \\
Contractors & 49 & 26 & $53.06 \%$ \\
Total & 204 & 118 & $57.84 \%$ \\
\hline
\end{tabular}

\subsection{Questionnaire Design and Data Collection}

Based on the literature review and expert opinion, 31 risk factors affecting project cost contingency were identified and tabulated for respondents to rate Respondents were requested to rate the above factors against a 10 point scale as $1=$ low probability/severity/impact and $10=$ high probability/severity/impact. All questionnaires were administered personally to the respondent during which advantage was taken to interview some top and middle level management staff for supplementary information.

\subsection{Data Analysis}

Based on the theoretical framework, qualitative risk analysis was undertaken using FMEA whilst quantitative risk analysis was undertaken using probabilistic risk estimation (evidential reasoning method). According to experience, historical antecedent, field knowledge and expert view, respondents developed their basic belief assignment in relation to three concepts. These concepts are likelihood of occurrence (L) of a risk factor, severity effect (I) of risk and detectability/hideability of the risk. Each of these concepts was expressed as an integer between 1 and 10, the Risk Priority Numbers (RPN) were estimated as follows:

$\mathrm{RPN}=$ severity $\mathrm{x}$ hideability $\mathrm{x}$ likelihood

Example:

RPN for Floods $=3.42 \times 6.87 \times 8.6=202.06$

$\mathrm{RPN}$ for substructure $=7.93 \times 7.94 \times 8.06=507.49$

The RPN for the risk factors and the work sections are displayed in Tables 2 and 3 respectively.

Quantitative risk analysis begun with the estimation of the risk of occurrence of each factor as:

Risk $=$ L x I

e.g. risk estimate for floods $=0.342 \times 6.87=0.23$ 
Table 2. Qualitative and quantitative risk analysis: cost contingency risk factors

\begin{tabular}{|c|c|c|c|c|c|c|c|}
\hline \multirow{2}{*}{ 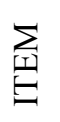 } & \multirow[t]{2}{*}{ Possible Risk Factor } & \multicolumn{4}{|c|}{ Qualitative Analysis } & \multicolumn{2}{|c|}{ Quantitative Analysis } \\
\hline & & $\mathrm{L}$ & I & $\mathrm{D}$ & RPN & RISK & PR \\
\hline A & Natural/ Environmental Risk & & & & & & \\
\hline 1 & Floods & 3.42 & 6.87 & 8.6 & 202.06 & 0.23 & 0.0224 \\
\hline 2 & Earth quakes, volcanic, landslides & 2.83 & 7.49 & 8.87 & 188.01 & 0.21 & 0.0202 \\
\hline 3 & Inclement weather & 4.06 & 8.6 & 8.53 & 297.83 & 0.35 & 0.0332 \\
\hline $\mathrm{B}$ & Technical Risk & & & & & & \\
\hline 4 & Design Failure/ Defective design & 5.46 & 7.08 & 6.88 & 265.96 & 0.39 & 0.0368 \\
\hline 5 & $\begin{array}{l}\text { Human resource management } \\
\text { challenges }\end{array}$ & 4.68 & 4.72 & 4.31 & 95.21 & 0.22 & 0.0210 \\
\hline 6 & Equipment Failure & 4.49 & 5.02 & 4.37 & 98.50 & 0.23 & 0.0214 \\
\hline $\mathrm{C}$ & Economic Risk & & & & & & \\
\hline 7 & Material supply challenges & 4.5 & 5.14 & 5.23 & 120.97 & 0.23 & 0.0220 \\
\hline 8 & Labour Supply challenges & 4.2 & 4.88 & 4.68 & 95.92 & 0.20 & 0.0195 \\
\hline 9 & Equipment availability challenges & 3.72 & 4.87 & 4.63 & 83.88 & 0.18 & 0.0172 \\
\hline 10 & Equipment productivity & 4.09 & 5.08 & 4.74 & 98.48 & 0.21 & 0.0198 \\
\hline 11 & Market conditions & 5.3 & 6.41 & 5.62 & 190.93 & 0.34 & 0.0323 \\
\hline $\mathrm{D}$ & Financial Risk & & & & & & \\
\hline 12 & Interest rate challenge & 5.57 & 7.1 & 6.66 & 263.38 & 0.40 & 0.0376 \\
\hline 13 & Delayed payment problems & 7.32 & 7.08 & 5.2 & 269.49 & 0.52 & 0.0493 \\
\hline 14 & Inflation and Market conditions & 7.09 & 7.81 & 6.02 & 333.34 & 0.55 & 0.0527 \\
\hline 15 & Global economic pressure & 6.13 & 6.13 & 5.96 & 223.96 & 0.38 & 0.0357 \\
\hline $\mathrm{E}$ & Design Risk & & & & & & \\
\hline 16 & Differing site conditions & 7.08 & 7.57 & 7.9 & 423.41 & 0.54 & 0.0510 \\
\hline 17 & Design completeness or status & 8.03 & 8.59 & 7.52 & 518.71 & 0.69 & 0.0656 \\
\hline 18 & Changes scope & 8.52 & 8.96 & 7.2 & 549.64 & 0.76 & 0.0726 \\
\hline 19 & Project complexity & 6.09 & 4.88 & 6.52 & 193.77 & 0.30 & 0.0283 \\
\hline 20 & Incomplete scope definition & 8.62 & 8.93 & 5.8 & 446.46 & 0.77 & 0.0732 \\
\hline 21 & Construction technology & 5.07 & 4.72 & 5.37 & 128.51 & 0.24 & 0.0228 \\
\hline 22 & Changes in specification & 6.55 & 6.26 & 5.57 & 228.39 & 0.41 & 0.0390 \\
\hline 23 & Estimation errors/ method & 5.81 & 5.15 & 3.87 & 115.80 & 0.30 & 0.0285 \\
\hline $\mathrm{F}$ & Governmental/Social Risk & & & & & & \\
\hline 24 & Contractual/procurement related & 5.6 & 5.21 & 4.16 & 121.37 & 0.29 & 0.0278 \\
\hline 25 & Governmental influence/intervention & .93 & 4.88 & 4.68 & 135.43 & 0.29 & 0.0275 \\
\hline 26 & Legislative/ statutory & 5.04 & 4.37 & 4.72 & 103.96 & 0.22 & 0.0210 \\
\hline 27 & Customary rights and litigation & 4.25 & 3.63 & 4.31 & 66.49 & 0.15 & 0.0147 \\
\hline $\mathrm{G}$ & Construction Risk & & & & & & \\
\hline 28 & Defects in supervision & 6.67 & 3.92 & 4.52 & 118.18 & 0.26 & 0.0249 \\
\hline 29 & Safety & 4.87 & 4.58 & 3.85 & 85.87 & 0.22 & 0.0212 \\
\hline 30 & Quality of work & 4.57 & 4.06 & 3.76 & 69.76 & 0.19 & 0.0177 \\
\hline 31 & Location & 5.22 & 4.68 & 4.6 & 112.38 & 0.24 & 0.0232 \\
\hline
\end{tabular}


Table 3. Qualitative and quantitative risk analysis: work section prone scope changes

\begin{tabular}{|c|c|c|c|c|c|c|c|c|}
\hline \multirow{2}{*}{$\sum_{\text {出 }}$} & \multirow[t]{2}{*}{ Possible Risk Factor } & \multicolumn{4}{|c|}{ Qualitative Analysis } & \multicolumn{2}{|c|}{$\begin{array}{c}\text { Quantitative } \\
\text { Analysis }\end{array}$} & \multirow[t]{2}{*}{ Remarks } \\
\hline & & $\mathrm{L}$ & $\mathrm{I}$ & $\mathrm{D}$ & RPN & RISK & PR & \\
\hline 1 & Substructure & 7.93 & 7.94 & 8.06 & 507.49 & 0.63 & 0.11376 & Highly relevant \\
\hline 2 & $\begin{array}{l}\text { Floor space } \\
\text { designation }\end{array}$ & 5.4 & 5.4 & 5.40 & 157.46 & 0.29 & 0.05269 & Irrelevant \\
\hline 3 & Structural framework & 6.02 & 6.98 & 6.02 & 252.96 & 0.42 & 0.07592 & $\begin{array}{l}\text { Moderately } \\
\text { relevant }\end{array}$ \\
\hline 4 & Block work & 6.85 & 6.85 & 6.85 & 321.42 & 0.47 & 0.08478 & $\begin{array}{l}\text { Moderately } \\
\text { relevant }\end{array}$ \\
\hline 5 & Carpentry & 5.02 & 5.02 & 5.02 & 126.51 & 0.25 & 0.04553 & Irrelevant \\
\hline 6 & Joinery & 5.44 & 5.44 & 5.44 & 160.99 & 0.30 & 0.05347 & Irrelevant \\
\hline 7 & Roofing & 6.49 & 6.49 & 6.49 & 273.36 & 0.42 & 0.07610 & $\begin{array}{l}\text { Moderately } \\
\text { relevant }\end{array}$ \\
\hline 8 & Finishes & 7.65 & 7.64 & 7.75 & 452.96 & 0.58 & 0.10560 & Highly relevant \\
\hline 9 & Electrical and IT & 7.83 & 7.9 & 7.90 & 488.67 & 0.62 & 0.11176 & Highly relevant \\
\hline 10 & $\begin{array}{l}\text { Mechanical } \\
\text { installations }\end{array}$ & 7.89 & 7.86 & 7.77 & 481.86 & 0.62 & 0.11205 & Highly relevant \\
\hline 11 & External works & 6.83 & 6.82 & 6.78 & 315.82 & 0.47 & 0.08416 & $\begin{array}{l}\text { Moderately } \\
\text { relevant }\end{array}$ \\
\hline 12 & $\begin{array}{l}\text { Furniture } \\
\& \text { Fenestration }\end{array}$ & 6.83 & 6.82 & 6.78 & 315.82 & 0.47 & 0.08416 & $\begin{array}{l}\text { Moderately } \\
\text { relevant }\end{array}$ \\
\hline
\end{tabular}

Source: Author's field survey, 2011

Table 4. Financial impact of the matrix of risk factors affecting work sections

\begin{tabular}{|c|c|c|c|c|c|c|c|c|c|c|c|c|c|}
\hline \multirow{2}{*}{$\sum_{\text {至 }}$} & \multirow{2}{*}{$\begin{array}{c}\text { Possible Risk } \\
\text { Factor }\end{array}$} & \multicolumn{3}{|c|}{ Substructure } & \multicolumn{3}{|c|}{ Electricals } & \multicolumn{3}{|c|}{ Mechanical Installations } & \multicolumn{3}{|c|}{ Finishes } \\
\hline & & $\mathrm{m}(\mathrm{s})$ & bel(s) & $\mathrm{pl}(\mathrm{s})$ & $\mathrm{m}(\mathrm{s})$ & $\operatorname{bel}(\mathrm{s})$ & $\mathrm{pl}(\mathrm{s})$ & $\mathrm{m}(\mathrm{s})$ & $\operatorname{bel}(s)$ & $\mathrm{pl}(\mathrm{s})$ & $\mathrm{m}(\mathrm{s})$ & $\operatorname{bel}(s)$ & $\mathrm{pl}(\mathrm{s})$ \\
\hline \multirow{3}{*}{1} & $\begin{array}{l}\text { Incomplete } \\
\text { scope }\end{array}$ & 0.0083 & 0.0083 & 0.9541 & 0.0082 & 0.0082 & 0.9549 & 0.0082 & 0.0082 & 0.9548 & 0.0077 & 0.0077 & 0.9574 \\
\hline & definition & & & & & & & & & & & & \\
\hline & $\begin{array}{l}\text { Design } \\
\text { completeness }\end{array}$ & 0.0075 & 0.0075 & 0.9624 & 0.0073 & 0.0073 & 0.9631 & 0.0074 & 0.0074 & 0.9630 & 0.0069 & 0.0069 & 0.9651 \\
\hline \multirow[t]{2}{*}{2} & / status & & & & & & & & & & & & \\
\hline & $\begin{array}{l}\text { Changes } \\
\text { scope }\end{array}$ & 0.0083 & 0.0083 & 0.9699 & 0.0081 & 0.0081 & 0.9704 & 0.0081 & 0.0081 & 0.9704 & 0.0077 & 0.0077 & 0.9721 \\
\hline & $\begin{array}{l}\text { Differing site } \\
\text { conditions }\end{array}$ & 0.0058 & 0.0058 & 0.9782 & 0.0057 & 0.0057 & 0.9785 & 0.0057 & 0.0057 & 0.9785 & 0.0054 & 0.0054 & 0.9797 \\
\hline 4 & $\begin{array}{l}\text { Changes in } \\
\text { specification }\end{array}$ & 0.0044 & 0.0044 & 0.9840 & 0.0044 & 0.0044 & 0.9842 & 0.0044 & 0.0044 & 0.9842 & 0.0041 & 0.0041 & 0.9851 \\
\hline 5 & $\begin{array}{l}\text { Delayed } \\
\text { payment }\end{array}$ & 0.0056 & 0.0056 & 0.9884 & 0.0055 & 0.0055 & 0.9886 & 0.0055 & 0.0055 & 0.9886 & 0.0052 & 0.0052 & 0.9892 \\
\hline & problems & & & & & & & & & & & & \\
\hline \multirow{2}{*}{$\begin{array}{l}6 \\
7\end{array}$} & $\begin{array}{l}\text { Market } \\
\text { conditions }\end{array}$ & 0.0060 & 0.0060 & 0.9940 & 0.0059 & 0.0059 & 0.9941 & 0.0059 & 0.0059 & 0.9941 & 0.0056 & 0.0056 & 0.9944 \\
\hline & TOTALS & $4.59 \%$ & 0.0459 & 0.9541 & $4.51 \%$ & 0.0451 & 0.9549 & $4.52 \%$ & 0.0452 & 0.9548 & $4.26 \%$ & 0.0426 & 0.9574 \\
\hline
\end{tabular}

Source: Author's field survey 
Table 5. Combination hypothesis using evidential method

\begin{tabular}{|c|c|c|c|c|}
\hline Subset Definition & $2^{\Omega}$ & $m(a)$ & $\operatorname{bel}(a)$ & $p l(a)$ \\
\hline Empty set & $\varnothing$ & & & \\
\hline Substructure & $\mathrm{s}$ & 0.0459 & 0.0459 & 0.8980 \\
\hline Electrical & e & 0.0451 & 0.0451 & 0.8079 \\
\hline Mechanical installation & $\mathrm{m}$ & 0.0452 & 0.0452 & 0.8960 \\
\hline Finishes & $\mathrm{f}$ & 0.0426 & 0.0426 & 0.8856 \\
\hline Substructure and Mechanical & sum & 0.0911 & 0.1822 & 1.0000 \\
\hline Substructure and electrical & sne & 0.0910 & 0.1820 & 1.0000 \\
\hline Substructure and finishes & snf & 0.0885 & 0.1770 & 1.0000 \\
\hline Electrical and mechanical installations & eum & 0.0903 & 0.1806 & 1.0000 \\
\hline Electrical and finishes & euf & 0.0877 & 0.1754 & 1.0000 \\
\hline Mechanical and finishes & muf & 0.0878 & 0.1756 & 1.0000 \\
\hline Substructure and electrical and mechanical & sueum & 0.1362 & 0.5448 & 1.0000 \\
\hline Substructure and electrical and finishes & sueuf & 0.1336 & 0.5344 & 1.0000 \\
\hline Substructure and electrical and finishes & sumuf & 0.1337 & 0.5348 & 1.0000 \\
\hline Electrical and mechanical installations and finishes & eumuf & 0.1329 & 0.5324 & 1.0000 \\
\hline $\begin{array}{l}\text { Substructure and electrical and mechanical and } \\
\text { finishes }\end{array}$ & $\Omega$ & 0.1788 & 1.0000 & 1.0000 \\
\hline
\end{tabular}

Source: Author's field survey

To determine the masses of the various risks using the evidential reasoning method, probabilistic estimation of risk was employed calculated as follows

$\mathrm{P}(\mathrm{r})=$. Risk

$$
\sum \text { Overall risk }
$$

Example the estimated probabilistic estimate for changes in scope $=0.76 / 10.51=0.726$

Where 10.79 is the summation of all risk $=0.23+0.21$ $+0.35+\ldots \ldots . .+0.19+0.24$

Tables 2 and 3 displays the RPN of the estimated risk and likelihood of work sections yielding to scope changes.

Based on the DST rule, the mass mappings are calculated and displayed in Table 4

The mass for substructure in relation to market condition/ inflation is $=0.11376 \times 0.0526=0.0060$

The mass for electrical in relation to changes in specification $=0.11176 \times 0.0390=0.0044$

In DS belief and plausibility provide the upper and lower bounds of probability for a proposition;

From eqn (4), $\operatorname{Bel}(\mathrm{A})=1-\mathrm{pl}(\mathrm{A})$

Again from equation 1, 5 and 6,

$P l$ (substructure/Incomplete scope definition) $=1-\sum$ $(\Omega)=1-(0.008+0.007+0.008+0.005+0.004+0.005+0.006+$ $0.002)=0.951$

From equation 6 , for a single mapping scenario,

$p l(A)=m(A)$ as depicted in Table 4 and 5

Thus $m$ (substructure/Incomplete scope definition) $=0.0083=$ belief

For the combination hypothesis displayed in Table 5, the belief in the set of hypotheses ssubstructure and mechanical installations $\}$ is the sum of its own basic assignment with those of all its subset.

$$
\begin{aligned}
& \{\mathrm{s}\},\{\mathrm{m}\},\{\mathrm{s} \mathrm{U} \mathrm{m}\} \mathrm{C}\{\mathrm{s} \mathrm{u} \mathrm{m}\} \\
& \quad \text { bel }\{\mathrm{s} \mathrm{u} \mathrm{m}\}=0.0459+0.0452+0.0911=0.1792
\end{aligned}
$$

the corresponding doubt estimate for $\{\mathrm{s} \mathrm{u} \mathrm{m}\}$

\section{1-belief $=0.8208$}

Estimating the plausibility for combination hypothesis as depicted in Table 6, takes into consideration all the basic assignments which got at least one hypothesis with those of the discussed statement in common. The sum of which must not exceed 1. For eg given $\{\mathrm{s} \mathrm{u} \mathrm{m}\}$, we would have its plausibility as

$\{\mathrm{s}\},\{\mathrm{m}\}\{\mathrm{s} \mathrm{u} \mathrm{m}\}\{\mathrm{s} \mathrm{u}$ e $\}\{\mathrm{s} \mathrm{u} \mathrm{f}\}\{\mathrm{m} \mathrm{u}$ e $\}\{\mathrm{f} \mathrm{u} \mathrm{m}\}\{\mathrm{s} \mathrm{u} \mathrm{e} \mathrm{u}$ $\mathrm{m}\}\{$ s u m u f $\}\{$ s u m u $\} \leq 1$

\section{Discussions}

The nature, likely occurrence, possible impact and "detectability" of a risk vary from one factor to the other. Though a risk factor may have a very high likelihood of occurrence, its impact upon occurrence may be negligible; hence may require little or no risk response planning for the said risk. Although other risk may have a very low probability of occurrence, the high corresponding impact may be overwhelming hence derailing other activities and cost centres. The above scenarios are particularly evident in project specific risk.

Qualitative risk analysis based on FMEA revealed seven risk factors as highly significant (Table 2). These risks includes incomplete scope definition, changes in scope, design completeness, differing site conditions, market conditions and delayed payment problems. These had RPN of 446, 549, 518, 423, 333 and 269 respectively from Table 2. With respect to the work sections, qualitative risk analysis revealed that four work sections are prone to high cost uncertainties and scope changes possibly affecting the final cost of the project as displayed in Table 3. These work sections are substructure, electrical services installations, mechanical services installations, and finishes; with corresponding probability values of $0.113,0.105,0.111$ and 0.112 respectively

Using the evidential reasoning method, the mass, belief and plausibility of the matrix impact of the work sections and risk factors are displayed in Table 4 . It can be 
upheld from Table 4 that overall impact of the systemic risk and project specific uncertainties yields an approximate financial impact of $4.59 \%$ of the substructure. Correspondingly, essential building services contributed $4.51 \%$ and $4.52 \%$ with respect to electrical and mechanical installations respectively. Another work section prone to high scope changes is finishes which accounted for $4.26 \%$ of the cost overruns drivers.

By integrating the combination hypothesis of the evidential reasoning method, multiple evidenced could be modeled as displayed in Table 5. From Table 5, given that the risk factors are fixed, the combined belief of any two work sections results in a minimum hypothesis of $8.77 \%$ (electrical and finishes). The maximum combined hypothesis of $9.11 \%$ is deduced from substructure and mechanical installations. Using the combination rule for three hypotheses, a maximum matrix mass of $13.62 \%$ deduced for substructure, electrical and mechanical installations. Correspondingly, a matrix mass of $13.29 \%$ was estimated for electrical, mechanical and finishes. The overall combined effect of the elements (singleton) of the frame of discernment, $\Omega$ gives a range of $17.88 \%$ to $24.55 \%$. The worst case scenario arises as result of effect of unstable microeconomic factors, market conditions and delayed payment problems.

\section{Implication for Practitioners}

According to Buertey et al. (2012b), there is no systematic process of estimating cost contingency in Ghana. A summary of the analysis of secondary data of contract documentation revealed that the estimation of cost contingency was based on organizational process asset (organizational culture, practices and historical data) and enterprise environmental factors. The above process however lacks a scientific risk management process. Estimating cost contingency using evidential reasoning method has shown that an average contingency factor of between $17.88 \%$ and $24.55 \%$ is required to make projects successful. An allowance of $17.88 \%$ is required to cater for design contingency and construction contingency primarily in the area of scope definition and enterprise environmental factors. The above notwithstanding, a factor of about $24.55 \%$ is required to cater for design risk and economic risk.

Design risk was identified by respondents as the risk category with the highest number of factors in terms of likelihood of occurrence and corresponding severity effect. Ethnographic studies reveal that scope management is the major factor affecting the allocation and management of construction projects. This is either evidenced in incomplete design, incomplete scope definition by client or changes in specification. A major category affecting the design management is challenge of poor site assessment survey and inadequate site engineering studies. The above mostly results in erroneous assumptions for the substructure. The impact of these differing site conditions is so significant and poses a major challenge for the cost management process.

Survey results have shown that the effect of financial risk (Delayed payment, unstable micro economic indicators etc) inflation cannot be overemphasized. Delayed payment of over three to six months has the propensity to seriously affect the cash flow status of the project with the resulting secondary risk (claims arising from interest in delayed payment). The effect of ascending inflation on project cost cannot be overemphasized, since this result in contractors experiencing hikes in labour, material and plant cost; with its attendant request for fluctuation to compensate for reduced margins.

The implemented model in Fig. 2 holds that the process of risk management must be contemporaneous with the various phases of project management and cost cycles. An integrated design management effort requires that the design phase, risk management phase and cost management phase move concurrently along the project trajectory.

At the conceptual stage of the project, risk management planning, cost planning and feasibility studies must be concurrent in nature. At this preliminary design stage risk identification and cost forecasting must be contemporaneous. This integrated effort of intertwined risk; cost and design phases shall follow a cyclical evolution until the project lunches into the execution stage. To manage the above process effectively, a cognitive design management effort is required with early communication of risk triggers.

From the implemented model in Fig. 2 above, a systematic process of risk identification, risk estimation and risk analysis is recommended using a cyclic evolution process. By means of organizational process asset and historical data, risk analysis would be enhanced through team by employing various tools. At concept formation stage, it is imperative that a quick risk overview using historical data, lessons learned and existing organizational process asset be employed. Fig. 2 holds that initial risk could be uncovered using tools such as brain storming, focus group discussions and Delphi techniques at the institutional level. Subsequent to the above, a thorough design process shall be undertaken during which the scope management process shall be established and well defined taking into consideration technical specification, construction technology, procurement and contract form. The risk identified at the institutional stage and the designs process shall influence the risk management process to be adopted and shall form a basis for the risk identification, assessment, response planning, monitoring and control, and risk review. As depicted in Fig. 2, the final stage of the above process shall be the use of external risk assessment process through the adoption of design management process, cognitive variables to confirm the risk level and impact of variables affecting construction cost contingency. 


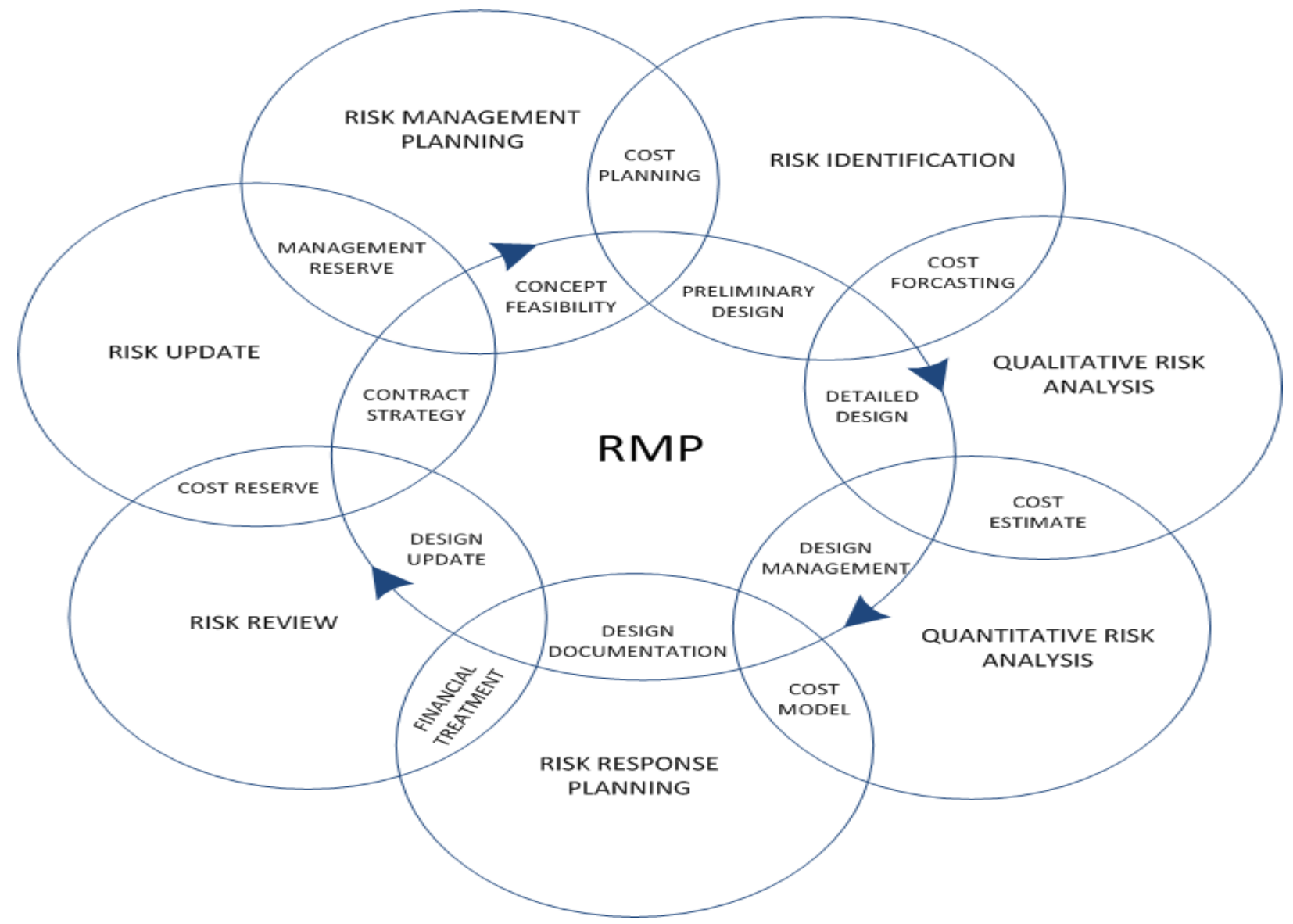

Source: Author's construct

Fig. 2. Implemented model: cost contingency estimation

\section{Conclusions}

This paper reviews the risk management process of contingency estimation holding that the deterministic method of contingency estimation lacks basis and confidence for the management of uncertainties on construction projects. The authors present the use of risk categorization and analysis to determine the most important risk taking into consideration organisational process asset, and external project variables. The result of the combination hypothesis for the DST calculus describing the subjective and objective viewpoint as an assessment for unknown fact is presented. The mass functions which are the responses of expert's view which formed the basis for determining the belief functions of subjective probability are also discussed. It can be concluded that DST hence gives professionals degrees of belief rather than a single point estimate which is associated with the Bayesian statistical model; which has varied inconsistencies resulting from so much subjective probability. Thus the advantage of the DST as a mathematical tool which permits simulation with the absence of preference, due to limitations of the available information which results from indeterminacy is worth commending.

It can be concluded that design risk with emphasis on scope changes, incomplete scope definition, changes in specifications, design completeness and differing site conditions are the most critical cost risk. Others economic risk such as micro and macroeconomic indicators and delayed payment problems can be said to be the secondary factors which as well affect the project cost risk during the cost contingency estimation process. Contrary to the $10 \%$ syndrome used by practitioners in Ghana, the overall combined effect of the matrix of risk factors and work section (singleton) of the frame of discernment, $\Omega$ gives a contingency range of $17.88 \%$ to $24.55 \%$. The above challenge could be a reason why in Ghana over $95 \%$ of projects are completed on time and having cost management challenges.

\section{References}

Ali, R. (2005). The Application of risk management in infrastructural construction project. Journal of Cost Engineering, 47(8), 20-27.

Aven, T. (2008). Perspective on Risk in Decision Making Context-Review and Discussion. Journal of Safety Science, 47, 798-806.

Buertey, J. T.I., Abeere-Inga, E., and Adjei-Kumi, T. (2012a). Estimating Cost Contingency for Construction Projects, the impact of systemic and Project specific risk. Journal of Construction Project Mgt and Innovation, 2(1).

Buertey, J. T.I., Abeere-Inga, E., and Adjei-Kumi, T. (2012b), Practical Application of Risk Management Techniques in Infrastructural Delivery. Proceedings of 1st International Conference on Infrastructure Development in Africa at KNUST, Kumasi.

Buertey, J. T.I., Abeere-Inga, E., and Adjei-Kumi, T. (2012c). Successful Delivery of Infrastructural Projects: Epistemic Overview of Cost Risk and Uncertainties. Proceedings of 1st International 
Conference on Infrastructure Development in Africa at KNUST, Kumasi, 22nd - 24th March 2012.

Clark, G. M. and Cook, D. (1998). A basic course in statistics. 4th Ed, New York, Arnold.

Keith, R. M. (2005). Programmatic cost risk analysis for highway megaprojects. J. Constr. Manage, 131, 343.

Keith, R M. (2011). A risk based approach to contingency estimating in highway project development. American Society of Civil Engineers, 786-795.

Kumar, R. (1999). Research methodology: A step by step guide for beginners, London, SAGE Publications.

Nasirzadeh, f., Afshar, A., Khanzah, M., and Howick, S. (2008). Integrating System Dynamics And Fuzzy Logic Modeling For Construction Risk Management. J. Construction Management and Economics, 26, 1197-1212.

Oyewobi, L. O., Ibrahim, A. D., and Ganiyu, B. O. (2012). Evaluating the impact of risk on contractor's tender figure in public buildings project in Northern Nigeria. EPPM Journal, 2(1), 2-13.

Ogunsanmi, O. E., Salako, O. A., and Ajayi, O. M. (2012). Risk classification model for designa dn build projects. EPPM Journal, 2(1), 2-13.

Perminova, O., Gustafsson, M., and Wikstrom, K. (2008). Defining Uncertainty in projects- a new perspective, Journal of Project Management, 26, 73-78.

Rakowsky, U. K. (2007). Fundamentals of the Dempster Shafer theory and its application to safety and reliability modeling, RTA, 3-4.

Rifat, S. (2007). Qualitative methodology for determination of cost contingency in international projects. Journal of Management in Engineering, 3539.

Tah, J. H. and Carr, V. (2000). Information modeling for the construction project risk management system. Journal of Engineering and Architectural Management, 7(2), 107-119.

Wishnu, B. O. and Pradono, P. (2011). Risk Treats in creative funding scheme for infrastructure projects in Indonesia: Cileunyi-Sumedang Toll Road project Case. Journal of Civil Engineering and Architecture, 5(1), 89-96.

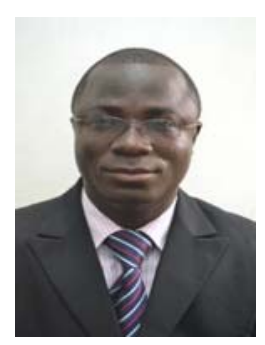

Joseph Teye Ignatius Buertey is a lecturer in Project management at the Pentecost University College. He has been in the academia for the past eight years. He is the also the Project, Development and Estate Manger of the Church of Pentecost. He holds a first degree in construction technology, a second degree in Construction management and currently undertaking his terminal degree in Engineering (Construction Project management). He is a Professional Member of the Ghana Institution of Surveyors (MGhIS); a Professional member of the Quantity Surveyors International (MQSi) and a certified Project Management Professional (PMP) and PMI. His interests of research are Procurement management, risk management, contract administration and project cost management.
Dr. Emmanuel Abeere-Inga is a civil engineer and project management specialist with over 15 years' outstanding experience in the design, planning and management of integrated development projects. For nearly 8 years (1997 to 2005), he led the multi-million dollar infrastructure delivery effort of ActionAid International in Ghana. He is currently the director of programs in a leading Ghanaian based development consultancy-CaRoRa Consultant and a parttime risk management lecture at the Accra Institute of Technology. Dr Abeere-Inga was educated in Russia and the United Kingdom respectively where he obtained the degrees of MSc in civil engineering (Moscow), MSc in management of projects (UMIST) and a PhD in civil engineering (Manchester). $\mathrm{He}$ is an Ogden teaching fellow, a member of Ghana institution of engineers and a graduate member of ICE, UK and has held several teaching positions at the University of Manchester. His current research interest includes; infrastructure delivery successes in developing, risk management, contingency cost estimations, urban growth and mobility.

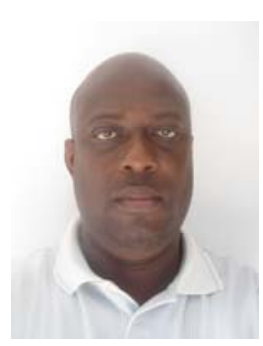

Dr. Theophilus Adjei-Kumi is currently a Lecturer at the Department of Building Technology in the Kwame Nkrumah University of Science and Technology (KNUST) in Ghana. He holds a $\mathrm{PhD}$ in Construction Management from Strathclyde University in Scotland. $\mathrm{He}$ is also a Professional Quantity Surveyor, a Project Management Professional, an Associate of the Chartered Institute of Arbitrators - UK and a Managing Consultant of a Project Management firm in Ghana. He has been in academia and industry for the past 14 years. His teaching and research interests are in Project Schedule, Cost, Risk and Procurement Management in the construction industry. 